\title{
Benefiting from Wrongdoing and Moral Protest
}

\section{Sigurd Lindstad ${ }^{1}$}

Accepted: 4 May 2021/ Published online: 10 May 2021

(C) The Author(s) 2021

\begin{abstract}
Some normative theorists believe that there is a principled moral reason not to retain benefits realized by injustice or wrongdoing. However, critics have argued that this idea is implausible. One purported problem is that the idea lacks an obvious rationale and that attempts to provide one have been unconvincing. This paper articulates and defends the idea that the principled reason in question has an expressive quality: it gets its reasongiving force from the symbolic aptness of such an act as an expressive response to wrongdoing. The paper thus argues that at least in a certain subset of cases, renouncing benefits realized by injustice amounts to a powerful and uniquely apt expression of protest against the disrespect for the victim that is implied by the wrongdoer's actions. The paper shows how this idea can inform the question of reparations for slavery and its aftermath in the United States. Lastly it develops an important objection to the argument presented and gives an account of how this objection can be met.
\end{abstract}

Keywords Benefiting from injustice $\cdot$ Expressive reasons $\cdot$ Corrective justice $\cdot$ Moral protest . Black reparations $\cdot$ Climate justice

\section{Introduction}

Some people think that it is morally objectionable to retain benefits that were realized by acts we deem to be injustices or wrongdoings. Arguably, George Orwell expressed this view (or something close to it) in The Road to Wigan Pier:

Sigurd Lindstad

sigurdlindstad@gmail.com

1 Department of Political Science, University of Oslo, Postboks 1097, Blindern, 0317 Oslo, Norway 
(...) [I]n order that England may live in comparative comfort, a hundred million Indians must live on the verge of starvation - an evil state of affairs, but you acquiesce in it every time you step into a taxi or eat a plate of strawberries and cream. ${ }^{1}$ (Orwell 1937:160).

One way to interpret this passage is that according to Orwell, benefiting from unjust actions can amount to acquiescing in the injustice. When we claim that a person acquiesces in something, that tends to mean that the person is taken to accept something. Moreover, acquiescence (of the sort Orwell is writing about here) means acceptance of a special sort: a tacit or implicit acceptance. When we claim that such acquiescence obtains, we take acceptance to be expressed by inaction or by silence. This is because we think that, given the situation, it would be apropriate for a person who did not accept the thing in question, to behave in certain ways that express that sentiment of non-acceptance. Suppose that this is the right understanding of the kind of acquiescence Orwell was aiming at. If so, his view was that in retaining the benefits of the empire we fail to express the morally apropriate protest for the wrongs we have benefited from.

My interest in this passage by Orwell is not interpretative. Regardless of what Orwell was really trying to say, I am interested in what we can call the expressive protest claim about the act of renouncing benefits that have been realized by wrongdoing. According to this claim:

One reason we have to renounce benefits realized by wrongdoing is that doing so expresses a kind of protest for the wrong.

Recently, there has been a growing literature on the idea that one should not retain benefits realized by injustice or wrongdoing. ${ }^{2}$ However, critics have argued that this idea is implausible. One purported problem is that the idea lacks an obvious and plausible rationale; it is unclear why it is problematic to benefit from injustice, and attempts to explain it have been unconvincing. ${ }^{3}$ Regardless of whether this criticism gets things right or not about past attempts, the expressive protest claim is worth exploring in more detail. Not least because similar claims have been made in the recent literature, but left largely undeveloped. For instance, Edward Page briefly entertains the idea that retaining affluence realized by greenhouse gas emissions entail '(...) condoning the setbacks of interests to which their affluence can be historically linked' (Page 2012: 315). Commenting on Page, Clare Heyward briefly elaborates when she writes:

I agree that the refusal to surrender benefits can be regarded as expressing a morally repugnant attitude towards the victims of the unjust situation. (...) If an agent benefits from another knowingly acting unjustly, then the beneficiary might be accused of

\footnotetext{
${ }^{1}$ My italics. Cp. Jean-Paul Sartre's claim, from the preface to Franz Fanon's The wretched of the earth, that to be European is to be '(...) an accomplice of colonialism, since all of us without exception have profited by colonial exploitation.' (Sartre 1963: 1viii). I suspect that Sartre's use of the term 'accomplice' ('complice' in the original French version) hints at something very similar to what Orwell has in mind, although I am not at all sure. As far as I know, accomplice typically means a person who helps someone else commit a crime or do something morally wrong. However, I think it is hard to see how the purported fact that all Europeans have benefited from colonial exploitation shows that we have helped the people responsible for colonialization commit the moral crimes they committed.

${ }^{2}$ See e.g. Butt (2007), Couto (2018) Barry and Goodin (2014), Goodin (2013), Lindstad (2021). For an overview of the idea, see Pasternak (2017).

${ }^{3}$ See e.g. Huseby (2015), Knight (2013), Lindstad (2020).
} 
condoning the action if she keeps the benefits. Failure to surrender benefits indicates that wrongs committed against the victim do not matter. The victim might have a justifiable complaint against the beneficiary that to refuse to surrender the benefits sides with the perpetrator and in doing so treats him, the victim, as less than a moral equal. (Heyward 2014: 410).

These are interesting claims. However, the argument is explained in no more than a few sentences, leaving many questions. If these claims allude to much the same as the expressive protest claim, as I think they do, then the present paper picks up on some lose threads in the recent literature worth further development.

As I see it, the expressive protest claim raises three questions:

- What is meant by moral protest?

- Why does giving up benefits express moral protest?

- Even if giving up benefits expresses protest in whatever sense it does so, why is that relevant for what we should do with the benefits?

In this paper I will seek to answer these questions. In doing so I will outline what we can call the expressive protest argument. According to this argument, in cases where the prospect of realizing some benefit for someone was the intention behind a wrongful action, or can reasonably be thought to have featured in the justification of the wrongdoer, renouncing those benefits by transacting them to the victims (or to some other symbolically apropriate cause) is a powerful way of expressing moral protest for a wrong and standing up for the value of the victims. Moreover, the special symbolic aptness of such an act, and the importance to us of protesting wrongdoing in a way that stands up for the moral value of the victim, provides us with an intrinsic kind of reason to renounce such benefits.

The paper is structured in the following way: Section 2 outlines the kind of account of moral protest I want to build my further arguments on. Section 3 argues that, in certain types of cases at least, renouncing benefits that have been realized by a wrong, amounts to a symbolically apt expression of moral protest for that wrong. Section 4 argues that the special symbolic aptness of renouncing benefits in expressing moral protest, provides a reason to give up the benefits. Section 5 considers an important objection that can be raised against the expressive protest argument. Section 6 concludes.

\section{Moral Protest}

I am going to model the kind of account of moral protest I am after in this paper on Angela Smith's work on the nature of moral blame. According to Smith, the nature of moral blame is best understood in terms of a moral protest, where moral protest is understood

(...) as a challenge to, and a repudiation of, a certain moral claim implicit in the wrongdoer's behaviour (Smith 2013: 42). 
She goes on to claim that

[w] hether or not it is outwardly expressed, a person who blames "marks out" and "challenges" as unacceptable a certain moral presumption on the part of the wrongdoer - the presumption that the person he has wronged is not deserving of moral respect. (Smith 2013: 42).

According to Smith, in blaming we protest a wrong by challenging a disrespectful claim against the victim of the wrong which is implied by the actions of the wrongdoer.

'Not deserving of moral respect' is not very specific. However, I think it can be made more specific by exchanging it for a more substantial account of what makes acts wrong. For instance, contractualists may think that the implicit claim the wrongdoer makes about the victim is that she is not owed treatment that can be reasonably justified to her. Most conceptions of morality hold its subject matter to be in some sense about treating each other as fundamental equals. Moreover, to in some sense be about treating each other as fundamentally valuable beings. If this is about right, then the implicit claim a wrongdoer makes about the victim by wronging her consists of a denial of some combination of the two: A wrongdoer's actions display and thus express a denial of respect for the victim as fundamentally an equal and fundamentally a valuable being.

Could we say something more about why we should think that a wrongdoer expresses that the victim is not valuable, or not a moral equal, by virtue of her wrongful actions? I think the answer is that only if the victim was not owed treatment as a valuable being and as an equal (in the relevant sense) could the actions of the wrongdoer have been justified. Moreover, that by (knowingly) doing what she did, a wrongdoer expresses that her actions were indeed justified. Thus, her actions make the expressive claim that the victim was not owed treatment as an equal and as a valuable being.

If a wrongful act makes a disrespectful claim about the fundamental value and fundamental moral equality of the victim, then this plausibly calls for a response from the moral community which rallies around the value of the victim. The reason it is plausible to think that a response is called for is that silence lets the implicit claim of the wrongdoer stand uncorrected, unchallenged. For Smith this challenge is central to the nature of sentiments and expressions of blame. Even when blame is felt privately. My ambition for the rest of the paper is to take this idea and run a bit further with it, beyond blame. My hypothesis is that this idea explains the intuitions we have about the aptness of a broader array of responses to wrongdoing. In particular I am interested in the intuition that, in certain kinds of cases at least, one should not retain benefits realized by wrongdoing.

\section{Why Benefits?}

Why should we think that renouncing benefits realized by a wrong, amounts to an apt expression of protest for that wrong? As John Gardner quips about the supposed aptness of apology and reparations as responses to injustice: 'Why not dancing, taking a day of work, learning Arabic, or doodling in red ink?' (Gardner 2018: 95).

One way to explain the special symbolic aptness of giving up a benefit of a wrong, is through the logic of a well-established argument in the literature on benefiting from injustice provided by Daniel Butt. According to Butt, the problem with benefiting from injustice is 
(roughly) that it is not consistently reconcilable with condemning and regretting the injustice (Butt 2007: 143). As I understand the argument, it relies on two uncontroversial observations. First, that judging something as wrong; to condemn and regret it, is to judge that it ought not to have happened. Second, that the beneficiary would never have had the benefit, had the wrong never happened. Ergo: the conclusion that condemning a wrong and retaining benefits produced by that wrong would amount to a form of contradiction (a 'conceptual error', according to Butt). I think that this argument is mistaken in certain ways. The problem, as I see it, is that giving up the benefits will not undo the fact that the wrong happened. Therefore, it is not contradictory or mistaken to think that one can keep the benefits while one also thinks that the wrong should never have happened. ${ }^{4}$

However, building on Butt's reasoning, perhaps it makes sense to say that we can symbolically express our judgment that an act should not have happened by making the world more similar to a counterfactual world where the wrong did not happen. It is presumably the case that giving up benefits that are causal effects of wrongs makes the world more similar to a counterfactual world where the wrong did not happen. If so, it is plausible that giving up benefits can express the judgment that the wrong should not have happened. Even if it does not literally undo the fact that the wrong happened.

One problem for this suggestion is that it does not really explain the focus on benefits that have been realized by an injustice. Some of the causal effects of a wrong may be burdens for some and benefits for others, but these are not all the causal effects of wrongs. There are many ways in which acts make the world different than it would otherwise have been, that are neither particularly beneficial nor harmful. Suppose that it is discovered that had it not been for some horrible wrong, it is likely that my house would have been painted yellow instead of white. According to my suggested application of the logic of Butt's argument, repainting my house yellow would be a symbolically apt way of expressing that the acts in question should never have happened. I think that it is tempting to object that such a claim seems a bit strange. The problem seems to be that there are countless ways the world would have been different had not some wrongful actions happened. Therefore, the logic of Butt's argument offers no vindication of the idea that there is something symbolically speaking special about the act of renouncing benefits that have been realized by those wrongs. A possible response to this objection is that it is costly to give up benefits. Therefore, giving up benefits expresses a particularly strong commitment to the attitude that the act in question should never have happened. Undoing or reversing other effects of a wrong will often not have this same potential for expressing commitment. However, this response does not shake off the problems. While there will often be many non-costly acts that would make the world appear more similar to a counterfactual world where some wrong never happened, repainting one's house can be quite expensive. So, if I am willing to take on that cost to make the world more similar to a world where a wrong never occurred, then my commitment is similarly strongly expressed.

I think the preceding discussion has shown that whatever its virtues, Butt's argument is not helpful for my purposes in this paper. However, I think that there is an alternative, more plausible way of thinking about the symbolic quality of renouncing benefits as an act of protest for a wrong. Before I get to this account, I should say that I don't think its plausible that you

\footnotetext{
${ }^{4}$ See Lindstad (2020) for elaboration on this point. It is tempting to respond to this objection by pointing out that while giving the benefits to the victim will not literally undo the fact that the wrong happened, it would mitigate the harm done. However, this response does not explain why the benefits in particular needs to be given up in order to avoid contradiction or error. Anyone with capacity to help the victim, beneficiary or not, can contribute to such mitigation.
} 
always get a symbolically apt expression of moral protest from the act of renouncing benefits realized by wrongs. However, I think that this is plausible in certain kinds of cases. The kind of cases I have in mind are those where the prospect of realizing the benefits in question was part of the justification for, or intention behind the wrongs in the first place. ${ }^{5}$ Or at least, where the realization of the benefits in question corresponds to the justification for the wrongs in a way which makes it reasonable to hold that their realization furthers the wrongdoers cause.

Why this restriction to only a subset of cases? First, recall that Angela Smith thinks of moral protest as a repudiation of an implicit claim the wrongdoer makes about the victim, that she is not deserving of a certain amount of moral respect. Second, in cases where the realization of the benefit was intentional or featured in the justification of the wrongdoer, it is plausible to think that a part of this implicit claim the wrongdoer makes about the victim, just is that the realization of the benefits in question did in fact contribute to justify the wrongs in question. Because, only if the victim was not owed a certain amount of moral respect, could the realization of the benefits in fact have justified the wrong.

If this is about right, then I think that it is plausible to say that renouncing benefits that were intentional or whose realization can reasonably be seen as part of the justification behind the wrongs in the first place, represents an act which challenges and repudiates the way in which the wrongdoer's actions express a denial of moral respect for the victim. In doing so, it can express the kind of moral protest we are after. However, 'renouncing' is too open-ended: It seems integral to the question of whether protest can be expressed by renouncing benefits, that the benefits are given up for a particular purpose. Protest is not expressed by transacting the benefits to family or friends for instance. Instead, the benefits must be given up for some particular purpose that speaks to the expressive intent. If this is not possible, then arguably the symbolic power of renouncement disappears. One such purpose is the purpose of helping the victim of the wrong. In employing the benefits realized by a wrong to mitigate the harm done by the wrong, there is a symbolic reversal of the judgment that the harm inflicted on the victim was justified by the benefits realized. It is the idea of such a symbolic reversal of the message conveyed by the wrongdoing, which explains why renouncing benefits for certain purposes can express protest, while doing so for other purposes cannot.

An immediate problem with the kind of argument suggested here, is found in the suspicion that whatever certain acts expressively symbolize, they do so for the mere reason that within a culture, we have agreed that they do so. If so, our hopes to employ this idea to explain a reason to renounce benefits from wrongs may be stifled. At least if we aspire to ground such a reason in something with a more objective flavour than the arbitrary dictates of social convention.

For my purposes in this paper, I want to note two things in response to this worry. First, the idea that certain actions symbolically express objective meanings independent of social convention, is not particular to the argument presented in this paper. For example, T. M. Scanlon arguably makes the same claim in Moral dimensions (Scanlon 2008: 52-42). Another example is found in a recent article by David Viehoff when he writes that:

\footnotetext{
${ }^{5}$ Several contributors to the debate on benefiting from injustice have suggested that it matters whether the realization of the benefits in question were the intentions of the wrongdoer. See Couto (2018: 2171), DuusOtterström (2017), Haydar and Øverland (2014) and Parr (2016). However, outside of Parr's article, the significance of intention has been explained by intuitions about cases. For a discussion of Parr's explanation of the relevance of intentions in this context, see Lindstad (2020).
} 
Social status hierarchies, we may say, embody society's judgment that some people are fundamentally more important than others (...) There is thus an expressive dimension to social inequality, if by this we mean that such inequality matters centrally because it is reasonably taken to reflect a certain view of people's fundamental moral significance. (Viehoff 2019:19).

As I understand Viehoff, the appeal to an idea about what it is reasonable to take social inequality to (symbolically) express, is an appeal to an objective standard for (symbolic) expressive meaning. Suppose that the overall argument made by Scanlon, Viehoff or others is acceptable to us. If so, we have reason to also accept the role the same idea about objective symbolic meaning plays in the argument presented in the present paper.

My second response is simply to point to Bennett's attempt to elucidate, beyond mere appeal to intuition, the thought that the objective kind of meaning in question is possible. Commenting on the symbolic aptness of acts that express blame towards someone who has committed a wrong, he writes:

(...) the appropriateness of the symbolism is not simply conventional (at least if we mean by that that it is an intrinsically arbitrary marker that has its place because of a mutual agreement to use it in a certain way) but instead has to do with the fittingness of the action to the situation. In blaming we display our understanding of how to translate the significance of the situation of wrongdoing into action. (...). What is true in the claim that such behavior is conventional is the Fregean thought that, as with any individual proposition, any piece of symbolic behavior can only symbolize by virtue of its place in a wider language that contains myriad other expressive possibilities. Unlike the mystical claim that there are hidden "correspondences" that exist between different objects, the existence of which is prior to forms of human understanding being brought to bear, symbolic relations of the sort I am interested in cannot be thought to exist independently of the human ability to trace connections, similarities, resonances. But this lack of strict mind independence need not undermine the thought that these resonances, once noticed, can be compelling. (Bennett 2013: 77).

Suppose that something along these lines gets things right about symbolic actions. If so, it provides us with a theoretical grounding for the more intuitive idea which Scanlon and Viehoff appeal to.

In this section I have argued that renouncing certain benefits realized by wrongs can express a specific kind of repudiation for the wrong in question in a particularly symbolically apt way. I think that this idea is good fit for the intuition that there is something objectionable with retaining benefits realized by wrongs. However, we need to ask whether this line of argument can help us to also assess the question of whether there is a reason to renounce benefits realized by wrongs.

\section{Renouncing Benefits and Expressive Reasons}

Suppose that renouncing certain benefits realized by wrongs expresses protest for the injustice in question in the sense I argued above. Even so, it would still be fair to ask for an explanation for why this is relevant for what we should do with the benefits. 
One explanation consists in the idea that sometimes the reason for doing something is simply that it symbolically captures; does justice to, the importance of a situation to us. Again, I take this idea from Bennett, who writes:

(...) in performing an expressive action, one seeks to create an external manifestation that corresponds to one's inner state (or rather, the intentional content or object of that state, the way in which the state presents the situation to the subject), and that one does so simply in order to reflect, mark or acknowledge one's sense of the, in some way extraordinary, nature of the situation. (Bennett 2016: 85)

It seems that an expressive form of acknowledgment is possible to achieve with words. However, according to the idea I am appealing to here, some things can only be expressed in a fully satisfactory way with a particular symbolically apt action. Performing the action is a way of appreciating, of recognising something in a way which cannot be done (as symbolically aptly) in another way. According to Bennett:

The act is a symbol of the situation - or rather, it is expressively powerful insofar as it succeeds as a symbol of the situation - and the symbol manages to capture something about the situation that couldn't be captured otherwise (Bennett 2016: 85)

Note that even though Bennett calls the action in question an expressive one, the goal of the action is not to communicate with someone else. Rather the goal is simply to reflect, mark, acknowledge something in a particularly symbolically apt way:

One acts intentionally in creating the symbol, but the creation of the symbol is its own end in two ways. Firstly, the symbol reflects the nature of the situation, and thus moulds itself to the way the world appears to be rather than attempting to mould or re-shape the world (...); and secondly, in symbolic action simply to have marked or acknowledged the situation is regarded as sufficient goal in its own right. Symbolic action of this type succeeds when it reflects the world and does not need to be productive of further good. (Bennett 2016:85).

I think this idea can help us tell a plausible story for why there is a reason to renounce benefits realized by wrongs. Consider first Bennett's emphasis on the importance of a situation to us. The importance of the situation we find ourselves in when we are faced with wrongful actions which express disrespect for the moral value of the victims of those actions, is the importance of standing up for the moral value of the victim. Standing up for the value of the victim is called for, because this value has been challenged by the acts of the wrongdoer. Respect for the victim therefore favours that we protest the wrong in ways that rally around the idea of the victim as a moral equal and as a valuable being. Consider second the idea of an act which symbolically captures something about this situation that could not be captured as aptly in other ways. In section $3 \mathrm{I}$ argued that renouncing benefits in ways which express symbolic reversal of the justificatory logic of the wrongdoer, constitutes a particularly apt expression of protest for the claim the wrongdoer makes about the victim in acting as she did, for the reasons she did so. This seems to me a good explanation for why it is that renouncing such benefits is an act that symbolically captures a distinct kind of repudiation for the wrong which stands up 
for the value of the victim. Arguably, such an act constitutes a quite powerful symbol of repudiation and protest.

Perhaps expressing this kind of protest is valuable for its own sake, as I have suggested here. However, actions that aptly express repudiation for injustice, may also be important for eliciting a certain kind of trust on the part of the victim of a wrong. The trust in question is the victim's trust in the shared attitude among other members of the moral community of the authority of her moral standing or her value, which she is left with reason to doubt in the aftermath of serious wrongdoing. As Margaret Urban Walker writes:

(...) we require assurance that we count, if not to those who have violated trust, then to others who affirm our membership in a community that repudiates our mistreatment. The enemy of trust is the loss of assurance (...). (Walker 2006: 107)

(...) Serious wrongdoing requires acknowledgement and assurance, rather than indifference, denial, or abandonment, if a significant level of trust is to be regained either in the wrongdoers or, more commonly and urgently, in the larger community. (Walker 2006: 108)

Just as with the expression of protest itself, the trust in question here may have its own value; it may be something we have reason to want for its own sake. However, it is likely to also be instrumentally useful for promoting social harmony, or for the psychological welfare of the victim of a wrong.

At this point in the paper, I want to address two important questions about the applicability of this idea to certain kinds of situations. These questions are:

1. What does the expressive protest argument imply for cases in which most or all of the original victims are no longer around?

2. What does the expressive protest argument imply for cases in which the wrongdoer is still around, and were we have the ability to make her compensate the victim?

The question about the cases where the original victims are no longer around raises two difficulties. First, since the original victims are dead, we might doubt the idea that we still have a reason of respect for the victims to protest the wrongs. Second, in cases where the victims are dead, it is unclear whether there still exists agents we can transact the benefits to and get a similar kind of symbolic effect of reversal sketched in the account above.

The expressive protest argument is seemingly open to different stances on the first problem. Whether we can have moral obligations of respect towards the dead, is strictly speaking an open question for my purposes in this paper. However, I am inclined to think that we can. Therefore, I think we still have reason to act in ways which protest wrongs against the dead in apropriate ways. At least if those wrongs were of a particularly grievous nature. The second question is more complicated. I think the answer is that it depends a lot on the situation. As I have argued, the interesting thing about benefits whose realization were part of the justificatory logic of the wrongdoer, is that transacting these benefits to the victim constitutes a symbolic reversal of that justificatory logic. That is what gives such an act its symbolic power and distinctiveness as an act of moral protest. But in cases were the original victims are dead and gone, we cannot transact the benefits to the original victims. This means that in many possible cases, there is no one to which the benefits can be transacted in a way that gives us the kind of reason-providing symbolic reversal we are after. In those cases, the expressive protest 
argument does not provide reasons to give up the benefits. However, certain kinds of cases arguably do. Consider for instance the case of benefits realized by slavery and its aftermath in the United States. In this case, the wrongs in question were publicly justified by, and arguably also motivated by, an ideology of white racial supremacy. The close motivating and justifying connection between the ideology of white supremacy and the wrongs of slavery and its aftermath motivate the suggestion that part of the implicit claim of the wrongdoers was that realizing benefits to white people justified the enslavement and systematic maltreatment of black people.

Now, suppose that there are still many lingering material benefits or advantages that have been realized by these grave wrongs. Moreover, suppose that by and large these benefits are in the hands of white people. This outcome is entirely predictable. Moreover, this outcome corresponds neatly to the justificatory logic of the wrongdoers, which was that realizing benefits for white people justify enslaving and systematically mistreating black people. I think that these observations make it plausible to say that transacting such benefits to the descendants of the original victims, or to give them up for the purpose of doing something about racial inequality, are exactly the kinds of actions which would express a reversal of the justificatory logic of the wrongdoers. ${ }^{6}$

The second question concerned cases where the wrongdoer is still around, and we have the ability to make her compensate the victim. Making the wrongdoer pay, plausibly conveys a strong form of protest. However, the question of whether reasons of moral protest favour making the wrongdoer pay or favour using the benefits to compensate the victim, or some combination of the two, is something I want to leave an open question in this paper. This question does not seem to have any bearing on our assessment of the core idea under consideration here.

\section{The Sufficient Alternatives Objection}

I have argued that renouncing certain benefits realized by wrongs is a powerful way of expressing moral protest for a wrong and standing up for the value of the victims. Moreover, I have argued that the special symbolic aptness of such an act, and the importance to us of protesting the wrong in a way that stands up for the moral value of the victim, provides us with an intrinsic kind of reason to renounce such benefits for certain purposes, such as benefiting the victims. Call this the expressive protest argument for renouncing benefits realized by wrongs. I think that it is fair to say that all of the important steps in this argument draw on controversial ideas. However, suppose that we accept these steps. I think that the expressive argument still faces at least one important objection.

The objection I have in mind consists in the claim that there are alternative acts which represent sufficiently symbolically apt responses to wrongdoing. Moreover, that these acts do not involve giving up benefits realized by the wrongs in question. Call this the sufficient alternatives objection. One way to make this objection is to hold that expressing our moral protest for a wrong cannot plausibly require more of us than getting angry, or have sincere attitudes of blame towards the wrongdoer, or sincerely using words to publicly condemn the injustice.

${ }^{6}$ Cp. Bernard Boxill (1972). 
One response to this claim is that in many cases, certain symbolically apt actions make for much stronger, more potent expressions of our standing up for the value of the victim than what can be achieved with mere words, or other non-costly acts. Talk is cheap, so the saying goes. I think that part of the reason this phrase is a saying and not simply a trivial truth about the price of talking, is that the phrase is often intended to point out that mere talk fails to express a real commitment to the cause. ${ }^{7}$ Conversely, in taking on real costs of our own with a view to repair the harm done by a wrong, we rally around the value of the victim in response to the wrong in a way which is symbolically particularly strong because it expresses unambiguous commitment.

Unfortunately, this response leaves the expressive argument vulnerable to a second way of putting the objection. Namely in terms of the claim that symbolically apt and costly acts of moral protest of the kind we are after, are possible without having beneficiaries' foot the bill. In order to motivate this claim, consider the intuitive idea that regardless of whether we have benefited from a wrong, we tend in general to have stronger reasons to allocate resources to repair the harm done to a victim of a wrong than a victim of an accident that involved the same level of harm. Consider for instance the difference between Pink: a person harmed by a wrong against her, and a person that has been harmed through no fault of her own, by an accident. Call this person Grey. I think that according to our common-sense moral convictions, there are stronger reasons to repair the harm done to Pink than the harm that has befallen Grey, even if they are equally burdened through no fault of their own. Given that Grey and Pink are equally burdened and are equally faultless for their misery, the common-sensical stance that it is more important to help Pink than Grey, should be at least mildly surprising on reflection. However, I think that the explanation for this stance is reasonable. My suggestion is that while Grey also has reason to want the harm compensated, the accident does not constitute an implicit challenge against her moral value. Conversely, wrongful acts often do. The intuitive idea I am appealing to here is that by attempting to repair the harm done to the victim of a wrong, we do not simply make life easier for a person that has been harmed. We also express repudiation or contradiction for the claim the wrongdoer's actions make about the value of the victim of those actions.

This line of argument shows that appeals to the idea that actions speak louder than words, cannot do the trick alone. The response we are left with therefore, is the insistence that simply repairing the harm has its limits as an act of moral protest. Moreover, that there is a particular and unique symbolic aptness to the act of renouncing benefits, found in the way such an act reverses the justificatory logic of the wrongdoer. Someone impressed with this idea may say that this fact about the symbolic quality of such an act is what provides the reason to, at least sometimes, renounce benefits in particular.

\footnotetext{
$\overline{7}$ This claim construes the function of the phrase to be to point out what merely talking about a commitment expresses about your real commitment. On this account the phrase can be used by someone who does not in earnest doubt a person's real commitment. Admittedly, the phrase is also used as an accusation. In such cases, it is intended to convey the message: 'I do not believe in your commitment'. I suspect that when we say 'talk is cheap', we intend it to convey a bit of both of these meanings. I also think that sometimes we explicitly indicate that our intentions in using it are opposite of what they really are. Consider the phrase: 'I do not doubt your commitment to our relationship, but you know, talk is cheap'. I am sure this kind of phrase has been uttered many times by people who did in fact doubt a partner's commitment to the relationship. Conversely, we can imagine someone angrily using the phrase in an accusatory tone, but only because she desires some particularly strong expression of love or respect, not because she seriously doubts that this love and respect is really reflected in the other person's attitudes.
} 


\subsection{Concluding Remarks}

In this paper I have outlined the expressive protest argument in favour of the idea that certain benefits that have been realized by wrongdoing ought to be renounced. While I think that there are reasonable objections against this argument, I think it captures our intuitions about benefiting from wrongdoing very well. Most notably, it explains the intuition that retaining certain benefits from wrongdoing is conceptually similar to condoning the actions of the wrongdoer.

Acknowledgments For helpful comments on earlier drafts of this paper, I would like to thank Robert Huseby, Avia Pasternak, Erlend Langørgen, Göran Duus-Otterström, Jakob Elster, Søren Flinch Midtgaard, Frej Klem Thomsen, Sune Lægaard, Sebastian Conte, Jens Jørund Tyssedal, Kasper Lippert-Rasmussen and three anonymous referees of Ethical Theory and Moral Practice.

Code Availability (Software Application or Custom Code) Not applicable.

Funding Open access funding provided by University of Oslo (incl Oslo University Hospital).

Data Availability Not applicable.

\section{Declarations}

Conflicts of Interest/Competing Interests Not applicable.

Open Access This article is licensed under a Creative Commons Attribution 4.0 International License, which permits use, sharing, adaptation, distribution and reproduction in any medium or format, as long as you give appropriate credit to the original author(s) and the source, provide a link to the Creative Commons licence, and indicate if changes were made. The images or other third party material in this article are included in the article's Creative Commons licence, unless indicated otherwise in a credit line to the material. If material is not included in the article's Creative Commons licence and your intended use is not permitted by statutory regulation or exceeds the permitted use, you will need to obtain permission directly from the copyright holder. To view a copy of this licence, visit http://creativecommons.org/licenses/by/4.0/.

\section{References}

Barry C, Goodin RE (2014) Benefiting from the wrongdoing of others. J Appl Philos 31:363-376. https://oi. org/10.1111/japp.12077

Bennett C (2016) Expressive actions. In: Abell C, Smith J (eds) Emotional expression: philosophical, psychological and legal perspectives. Cambridge UP, Cambridge, pp 73-94

Bennett C (2013) The expressive function of blame. In: Coates DJ, Tognazzini NA (eds) Blame: its nature and norms. Oxford UP, Oxford, pp 66-83

Boxill B (1972) The morality of reparation. Soc Theory Pract 2:113-123. https://doi.org/10.5840/ soctheorpract1972216

Butt D (2007) On benefiting from injustice. Can J Philos 37:129-152. https://doi.org/10.1353/cjp.2007.0010

Couto A (2018) The beneficiary pays principle and strict liability: exploring the normative significance of causal relations. Philos Stud 175:2169-2189. https://doi.org/10.1007/s11098-017-0953-y

Duus-Otterström G (2017) Benefiting from injustice and the common source problem. Ethical Theory Moral Pract 20:1067-1081. https://doi.org/10.1007/s10677-017-9845-7

Gardner J (2018) From personal life to private law. Oxford UP, Oxford

Goodin RE (2013) Disgorging the fruits of historical wrongdoing. American Political Science Review 107:478491. https://doi.org/10.1017/S0003055413000233 
Haydar B, Øverland G (2014) The normative implications of benefiting from injustice. J Appl Philos 31:349362. https://doi.org/10.1111/japp. 12078

Heyward C (2014) Benefiting from climate geoengineering and corresponding remedial duties: the case of unforeseeable harms. J Appl Philos 31:405-419. https://doi.org/10.1111/japp.12075

Huseby R (2015) Should the beneficiaries pay? Politics, Philosophy, and Economics 14:209-225. https://doi.org/ $10.1177 / 1470594 X 13506366$

Knight C (2013) Benefiting from injustice and brute luck. Soc Theory Pract 39:581-598. https://doi.org/10.5840/ soctheorpract 201339433

Lindstad S (2020) What is the wrong in retaining benefits from wrongdoing? How recent attempts to formulate a plausible rationale for the 'beneficiary pays principle' have failed. Res Publica 26:25-43. https://doi.org/10. 1007/s11158-019-09420-9

Lindstad S (2021) Beneficiary pays and respect for autonomy. Soc Theory Pract 2021:153-169. https://doi.org/ 10.5840 /soctheorpract 2021129114

Orwell G (1937) The road to Wigan pier. Secker and Warburg, London

Page E (2012) Give it up for climate change: a defence of the beneficiary pays principle. International Theory 4 : 300-330. https://doi.org/10.1017/S175297191200005X

Parr T (2016) The moral taintedness of benefiting from injustice. Ethical Theory Moral Pract 19:985-997. https:// doi.org/10.1007/s10677-016-9706-9

Pasternak A (2017) Benefiting from wrongdoing. In: Lippert-Rasmussen K, Brownlee K, Coady D (eds) A companion to applied philosophy. Blackwell, Oxford, pp 411-423

Sartre J-P (1963) Preface to the wretched of the earth. Grove Press, New York

Scanlon TM (2008) Moral dimensions: permissibility, meaning, blame. Harvard UP, Cambridge

Smith AM (2013) Moral blame and moral protest. In: Coates DJ, Tognazzini NA (eds) Blame: its nature and norms. Oxford UP, Oxford, pp 27-48

Viehoff D (2019) Power and equality. Oxford Studies in Political Philosophy 5:3-38

Walker MU (2006) Moral repair: reconstructing moral relations after wrongdoing. Cambridge UP, Cambridge

Publisher's Note Springer Nature remains neutral with regard to jurisdictional claims in published maps and institutional affiliations. 